\title{
Biofuel promising plants and micropropagation
}

\section{Introduction}

The world is now heading for using oil alternatives in all areas of industry where the oil doomed to vanish. Biofuels in compared with fossil fuels, release fewer pollutants and greenhouse gases, such as carbon dioxide, into the atmosphere. Biofuels are sustainable and consists of two main categories: bioalcohol and biodiesel. Ethanol, which could be made from corn, wheat, sugarcane, etc., releases less carbon monoxide, nitrogen oxide and sulfur into the atmosphere than gasoline. Biodiesel is made from animal fats or vegetable oils and renewable resources that come from plants such as jojoba, jatropha, soybean, sunflowers, corn, olive, peanut, palm, coconut, safflower, canola, sesame, cottonseed, etc. ${ }^{1}$ The availability and sustainability of biodiesel resources will be the limiting factor in the widespread use of biodiesel. ${ }^{2}$ Biofuels could be applied, without competing food supply and planted areas, using non-edible plants which tolerate drought, salinity and high temperature and can be planted in areas unsuitable for planting food crops. Furthermore, waste and saline water can be used in irrigating these biofuel plants with limited need of drinking water consumption.

Jatropha and Jojoba are unique for biofuel production and they can tolerate the previous conditions. Jatropha is native to South America and widely distributed in South and Central America ${ }^{3}$ while, jojoba is native to Sonoron desert and North-west Mexico and Baja California. ${ }^{4}$ Jatropha seed contains $40-60 \%(\mathrm{w} / \mathrm{w})$ of non-edible oil. The oil contains $21 \%$ saturated fatty acid and $79 \%$ unsaturated fatty acid. ${ }^{5}$ It does not congeal at cool temperature and has some unique properties that make it suitable as a biodiesel. ${ }^{6}$ These properties are low acidity, good oxidation stability and low viscosity as compared to some other plant oils. ${ }^{7}$ Similarly, jojoba oil has most of the previous unique properties. ${ }^{8}$ Its oil has (97\%) of linear long- chain esters, which are characteristic components of waxes. ${ }^{9}$ More than $80 \%$ of these are esters of C18-, C20-, C22-, and C24- chain monounsaturated alcohols and fatty acids. ${ }^{910}$ Jojoba oil is an unusually pure compound with less than $3 \%$ triglyceride content and highly resistant to oxidation. ${ }^{8}$ Unlikely, Jojoba wax has many other applications in cosmetics and personal care formulations. ${ }^{11}$

Jatropha and jojoba can be established sexually from seeds or asexually by vegetative propagation. Cultivation of these plants with seeds shows high variation in growth, maturity and yield. Moreover, jojoba is a dioccious plant and its propagation with seed lead to give 1:1 sex ratio in the field. ${ }^{12}$ Thus, vegetative propagation is an important target for applying a large number of these plants with similarity and homogeny in growth and yield. Tissue culture application could be unique for clonally production of these plants.

\section{Shoot proliferation}

Jatropha and Jojoba attracted a huge interest in tissue culture, earlier in 1970's and 1980's. Srivastava ${ }^{13}$ and Srivastava et al., ${ }^{14}$ induced triploid roots and shoots from mature endosperm of Jatropha panduraefolia. Birnbaum ${ }^{15}$ developed a micropropagation method for jojoba using accelerated axillary bud. Coutino et al., ${ }^{16}$ stated that, jojoba stem node explants cultured with two lateral buds in a
Volume 4 Issue 6 - 2016

\author{
Rania A Taha \\ Pomology Department, National Research Centre, Egypt
}

Correspondence: Rania Abdel-Ghaffar Taha Khalil, Biotechnology and Micropropagation Fruit Trees Lab, National Research Centre, 33 El Bohouth st., Dokki, Giza, Egypt, Tel 0201224184078,Email rania_abdelghaffar@yahoo.com

Received: June 01, 2016 | Published: October 18, 2016

Murashige and Skoog medium (SM) containing cytokinins gave rise to new shoots bearing 15 nodes in all. Jauhar ${ }^{17}$ determined the best culture conditions and media for shoot and root formation from jojoba nodal and shoot segments. Recently, jatropha proliferation was achieved from petioles ${ }^{18,19}$ from leaf $\operatorname{disc}^{20}$ and from axillary nodes. ${ }^{21}$ Fayek et al., ${ }^{22}$ induced shoot multiplication of jojoba distinguished clone from shoot tip and nodal segments. Multiplication could be highly achieved by cytokinin but callus induction was applied using auxin alone or combined with cytokinin. In addition, presenting in vitro jojoba shoots to seawater levels increased shoots multiplication and callus cultures significantly. ${ }^{23,24}$ Laser irradiation was also investigated on jojoba in vitro culture. ${ }^{25}$

\section{Rooting}

Rooting and acclimatization of jojoba in vitro plantlets seemed to be difficult due to the low percentage of rooting obtained..$^{22}$ However some advantages were detected. ${ }^{26-29}$ Although Singh and Shetty ${ }^{30}$ indicated that jatropha is difficult to root, Daud et al., ${ }^{31}$ achieved $46 \%$ rooting. Moreover, Panghal et al., ${ }^{32}$ assured that jatropha shoots was highly rooted. The rooted plantlets were cultured in soil with more than $90 \%$ survival. That seemed to be dependent on easy to root clones or strains, age of started explants, type of auxins used in rooting media, etc.

\section{Oil}

Jojoba oil was not only obtained from seeds but also from various explants. In vitro callus cultures could be a source for jojoba oil..$^{24,33,34}$ Similarly, Demissie et al., ${ }^{35}$ determined fatty acids from somatic embryos of jatropha. However, it needs more research to enlarge oil amount for both plant in vitro. There is no doubt that in vitro culture of these promising plants needs more researches to determine a protocol for their micro propagation.

\section{Acknowledgement}

The author wish to thank the National Research Centre, 33 El Bohouth St (formal El Tahrir st.), Dokki, Giza, Egypt, P.O.12622, for funding this work.

\section{Conflict of interest}

The author declares no conflict of interest. 


\section{References}

1. Filemon A, Uriarte Jr. Biofuels from plant oils. The ASEAN Foundation, Jakarta, Indonesia; 2010. p. 1-144.

2. Pinzi S, Garcia IL, Lopez-Gimenez FJ, et al. The ideal vegetable oilbased biodiesel composition: a review of social, economical and technical implications. Energy Fuels. 2009;23(5): 2325-2341.

3. Mukherjee P, Varshney A, Johnson TS, et al. J. curcas: A review on biotechnological status and challenge. Plant Biotechnology Reports. 2011;5(3):197-215.

4. Benzioni A. Jojoba domestication and commercialization in Israel. Horti Rev. 1995; 17:233-266.

5. Gubitz GM, Mittelbach M, Trabi M. Exploitation of tropical oil seed plant J. curcas L. Bioresource Technology. 1999;67(1):73-82.

6. Gressel J. Transgenics are imperatives for biofuel crops. Plant Science. 2008;174(3):246-263.

7. Tapanes NCO, Aranda DA, Carrerro JW, et al. Transesterification of J. curcas oil glycerides: Theoretical and experimental studies of biodiesel reaction. Fuel. 2007;87(10-11):2286-2295.

8. El-Mallah MH, El-Shami SM. Investigation of liquid wax components of Egyptian jojoba seeds. J Oleo Sci. 2009;58(11):543-548.

9. Bhatia VK, Gulati IB. Chemistry and utilization of oil of jojoba. J Sci Ind Res. 1981;40:45-50.

10. Shani A. The struggles of jojoba. CHEMTECH. 1995;25(5):49-54.

11. Passerini E and Lombardo P. Cosmet News. 2000;22:396-398.

12. National Academy of Science. Jojoba-new crop for arid lands, new raw material for industry. Rep Ad Hoc Panel, Washington DC, USA; 1985.

13. Srivastava PS. In vitro induction of triploid roots and shoots from mature endosperm of Jatropha Panduraefolia. Z Pflanzen Physiol. 1975;66(1):93-96.

14. Srivastava PS and Johri BM. Morphogenesis in mature endosperm cultures of Jatropha panduraefolia. Beitr Biol Pflanzen. 1974;50:255-268.

15. Birnbaum E. Propagation of jojoba by tissue culture. Jojoba Happenings. 1982;39:11.

16. Coutino AD and Madrigal LR. In vitro propagation of jojoba (Simmondsia chinensis (Link) Schneider). Revista Chapingo. 1983;8: 39-41.

17. Jauhar PP. Micropropagation of jojoba cultivars. In Vitro. 1983;19:249.

18. Nasir NAN, Anuar N, Yaakob Z. Induction of multiple shoot bud formation from Jatropha curcas L. J App Sci Agr. 2014; 9(20):63-69.

19. Ying L, Tong X, Hui W, et al. Efficient culture protocol for plant regeneration from petiole explants of physiologically mature trees of Jatropha curcas L. Biotech Biotech Equip. 2015;29(3):479-488.

20. Mubashar NM, Rao DG, Dantu PK. In vitro shoot regeneration from leaf disc cultures. Indian J Plant Sci. 2015;4(4): 42-48.
21. Shrivastava S, Banerjee M. In vitro clonal propagation of physic nut (Jatropha curcas L.): influence of additives. Inter $J$ integ Boil. 2008;3(1):73-79.

22. Fayek MA, Shaaban EA, El-Obeidy AA, et al. In vitro propagation of three female jojoba clones (Simmondsia chinensis (Link) Schneider). Egypt J App Sci. 2007;22(6B):652-665.

23. Fayek MA, Shaban EA, Zayed NS, et al. Effect of salt stress on chemical and physiological contents of jojoba (Simmondsia chinensis (Link) Schneider) using in vitro culture. World J Agric Sci. 2010;6(4):446-450.

24. Taha RA. Effect of growth regulators and salinity levels on in vitro cultures of jojoba plants. World App Sci J. 2014;31(5):751-758.

25. Taha RA, Taha LS, Metwally SA. In vitro cultures of jojoba (Simmondsia chinensis L.) affecting by laser irradiation. J Chemi Biol Phys Sci, Sec B. 2015;5(4):3906-3913.

26. Agrawal V, Prakash S, Gupta SC. Effective protocol for in vitro shoot production through nodal explants of Simmondsia chinensis. Biol Plant. 2000;45:449-453.

27. Bashir MA, Rashid H, Anjum MA. In vitro shoot initiation from nodal explants of jojoba (Simmondsia chinensis) strains. Biotechnol. 2007;6:165-174.

28. Bashir MA, Rashid H, Anjum MA. In vitro shoot multiplication of six promising strains of jojoba (Simmondsia chinensis). Biotechnol. 2007;6:309-315

29. Bashir MA, Anjum MA, Rashid H. In vitro root formation in micropropagated shoots of jojoba (Simmondsia chinensis). Biotechnol. 2007;6:465-472.

30. Singh G, Shetty S. Evaluation of in vitro rooting efficiency in the biodiesel plant, Jatropha curcas Biotechnol. Bioinf Bioeng. 2012;2(1):591-596.

31. Daud N, Faizal A, Geelen D. Adventitious rooting of Jatropha curcas L. is stimulated by phloroglucinol and by red LED light. In Vitro Cell Dev Biol-Plant. 2013;49(2):183-190.

32. Panghal S, Beniwal VS, Laura JS. An efficient plant regeneration protocol from petiole explants of physic nut (Jatropha curcas L.). African J Biotechnol. 2012;11(63):12652-12656.

33. Gabr MF. Tissue culture of jojoba "Simmondsia chinensis Link" with special emphasis on establishing and shooting stages. Egy J Hort. 1993;20:145-160.

34. Aftab F, Akram S, Iqbal J. Estimation of fixed oil from various explants and in vitro callus cultures of Jojoba (Simmondsia chinensis). Pak J Bot. 2008;40(4):1467-1471

35. Demissie AG, Lele SS. Determination of polyunsaturated fatty acids in Jatropha curcas somatic embryos and the effect of abiotic sources. Biol Sci Pharmaceut Res. 2013;1(1):8-15. 